\title{
Optimal diagnosis, prevention, and management of periprosthetic joint infection
}

This article was published in the following Dove Press journal:

Orthopedic Research and Reviews

12 January 2015

Number of times this article has been viewed

\author{
Nathalie Tafer' \\ Wilson Belaieff' \\ Céline Cuérel' \\ Matthieu Zingg' \\ Pierre Hoffmeyer ${ }^{1}$ \\ Ilker Uçkay ${ }^{1,2}$ \\ 'Orthopedic Surgery Department, \\ ${ }^{2}$ Division of Infectious Diseases, \\ University of Geneva Hospitals and \\ Medical School, Geneva, Switzerland
}

\begin{abstract}
The pace of the aging population is steadily rising worldwide with a parallel increase in the demand for joint replacement procedures. With the increasing number of patients undergoing arthroplasty, there is also an increased risk for arthroplasty infection that may lead to severe complications, poorer outcome, and substantial extra costs for health care systems. Current rates of prosthetic joint infection are not dramatically different from the 1960s or 1970s, but some general principles are now better defined, and their management has been studied extensively during the past decades, thus resulting in a change in clinical practice. The purpose of this review is to summarize important principles of prosthetic joint infection to guide the clinician and to contribute to the optimal diagnosis, prevention, and management of periprosthetic joint infections.
\end{abstract}

Keywords: arthroplasty infection, antibiotic therapy, biofilm, surgery, prevention

\section{Introduction}

Advances in orthopedic surgical practice for arthrosis have benefited the aging population by providing pain relief and mobility. Hip and knee arthroplasty have now become the most frequent procedures with improved functional outcome due to the emergence of novel surgical techniques and an enhanced management of potential risks and complications. However, infection in orthopedic surgery is difficult to diagnose and treat as it can present different clinical manifestations and treatment response. Given the increasing number of arthroplasty and revision arthroplasty procedures carried out worldwide, surgical site infection is a potential serious threat as it can lead to dramatically worse clinical outcomes compared to the preoperative state. The prevention, identification, and treatment of early prosthetic joint infection (PJI) require a thorough understanding of complications to ensure patient quality of care and safety. The purpose of this review is to summarize important principles of PJI and to contribute to optimal diagnosis, prevention and management of periprosthetic joint infections.

\section{Epidemiology and costs}

Infection in orthopedic surgery is a frequently feared complication. It may result also in temporary prosthesis removal with or without replacement and, rarely, loss of the affected limb. ${ }^{1}$ The current reported rate of PJI for knee and hip arthroplasty is generally less than $2 \% .^{1-5}$ Published rates following orthopedic surgery range from $0.7 \%$ for low-risk patients undergoing primary hip replacement to $2 \%-5 \%$ in revision arthroplasty, shoulder arthroplasty, or fracture fixation devices, and as high as $7.9 \%$
Correspondence: Nathalie Tafer Orthopedic Surgery Department, University of Geneva Hospitals and Medical School, 4 Rue Gabrielle PerretGentil, I2II Geneva 14, Switzerland Tel +4I 795533482 Fax +4I 223729832

Email nathalie.tafer@hcuge.ch 
for high-risk patients undergoing spinal fusion. ${ }^{2,5}$ Tsara et al followed more than 7,300 total hip and knee arthroplasty procedures. ${ }^{6}$ Interestingly, they did not show a statistically significant difference in the incidence of PJI rates over four decades of implantation.

$\mathrm{PJI}$ also has a significant economic impact and can generate extra costs that may be two to three times higher than the expected costs of the initial operation and hospitalization. In a study published in 2002, Whitehouse et al reported that the development of surgical site infection following orthopedic surgery doubles a patient's risk of readmission to the hospital during the following 12 months, and more than triples the total direct cost of hospitalization, ${ }^{2}$ with extra costs estimated to be between US\$30,000-50,000. ${ }^{3}$ In 2007, one million total joint replacements were performed in the USA and it is estimated that this will increase to more than four million by 2030 . It is expected also that the incidence of PJI will increase. ${ }^{4}$ Thus, it is of the utmost importance to extend our current knowledge and to understand how to reduce PJI and its complications as far as possible.

\section{Prevention and hematogenous infection}

A number of risk factors have been highlighted. These include preoperative comorbidities, such as obesity and diabetes mellitus, and intraoperative factors, such as the aseptic technique, surgical skills, and the operating room environment, but the age or sex of patients does not appear to influence the outcome (Table 1). However, half of all identified risk factors are endogenous with a synergistic

Table I Frequent and important risk factors for prosthetic joint infection

\begin{tabular}{|c|c|c|}
\hline Preoperative & Intraoperative & Postoperative \\
\hline $\begin{array}{l}\text { Obesity and/or poor } \\
\text { nutrition }\end{array}$ & $\begin{array}{l}\text { Simultaneous bilateral } \\
\text { arthroplasty }\end{array}$ & Remote infection \\
\hline Diabetes mellitus & $\begin{array}{l}\text { Lack of prophylactic } \\
\text { antibiotic }\end{array}$ & Improper dressing \\
\hline Immune suppression & Cement without antibiotic & Hematoma \\
\hline Body carriage with & Duration of surgery & Continuous wound \\
\hline Staphylococcus aureus & $>2$ hours & discharge \\
\hline Rheumatoid arthritis & $\begin{array}{l}\text { Contaminated or dirty } \\
\text { surgical site and skin ulcers }\end{array}$ & $\begin{array}{l}\text { Prolonged hospital } \\
\text { stay }\end{array}$ \\
\hline $\begin{array}{l}\text { Previous surgery in the } \\
\text { same joint and history } \\
\text { of joint infection }\end{array}$ & $\begin{array}{l}\text { Concomitant remote } \\
\text { infection }\end{array}$ & Dehiscence \\
\hline \multicolumn{3}{|l|}{ History of joint } \\
\hline \multicolumn{3}{|l|}{ infection } \\
\hline \multicolumn{3}{|l|}{ Smoking } \\
\hline \multicolumn{3}{|l|}{ Preoperative anemia } \\
\hline Skin ulcers & & \\
\hline
\end{tabular}

potential, and they are difficult to modify in the immediate pre- and postoperative phase. . $^{1,5} 7$ The most effective evidencebased preventive measures are surgical hand preparation, appropriate antibiotic prophylaxis, and postponing of an elective operation if any risk factors can be changed. ${ }^{5,8,9}$ Surgical site infection in orthopedic surgery has some specificities, such as a low inoculum needed for infection, frequent biofilm formation on the foreign body or implant, or the possibility of hematogenous infection of the implant. ${ }^{5}$ Implant infection and biofilm formation can originate from direct inoculation or from hematogenous infection. ${ }^{10-12}$ Implants are susceptible to infection because they are devoid of a microcirculation that is critical for host immune defense and the delivery of antibiotics. Hematogenous infection accounts for approximately $10 \%$ of all PJI, with an incidence of $0.1 \% .^{5,6,10,11}$ It tends to appear far later than primary surgical site infection, usually beyond the first 12 months. However, it is not essential to identify the origin of a hematogenous infection, and the costs of complementary and often costly examinations (such as endoscopy or scanography) should be counterbalanced with the benefits to be obtained. From an epidemiologic standpoint, these examinations are often inconclusive and do not contribute to the management of PJI, apart from some microorganisms associated with the presence of cancer or occult abscesses, such as Clostridium septicum or Streptococcus bovis. If the origin of hematogenous infection is an abscess, it will be treated by the 6-week antibiotic therapy administered for PJI. To our knowledge, there is no study reporting recurrent infection after treatment, and the origin of hematogenous arthroplasty infection is best determined by the patient history in general. ${ }^{13}$

\section{Microorganisms}

Microorganisms involved in PJI often grow in biofilm that is composed of a self-developed polymeric matrix, where they are protected from antimicrobial agents and the host immune response. ${ }^{12,14}$ It is estimated that approximately $60 \%$ of all bacteria found in nature live in biofilms. Biofilm is composed of both offending pathogens and the host. After adherence to inert surfaces, such as prosthesis metal, bacteria form this matrix within only a few days. For example, during the acute phase of an infection, Staphylococcus aureus uses microbial surface components recognizing adhesive matrix molecules that specifically recognize, interact, and bind with extracellular matrix. In turn, this permits colonization and produces inflammation and sequestering microorganisms that produce matrix-lysing toxins. During the chronic phase, pathogens produce biofilm attached to the implants in which they can grow protected 
from the host immune defense. In contrast to their planktonic counterparts floating outside the biofilm, bacteria within the biofilm reduce their metabolism and divide less actively. As most antimicrobial (cell wall-acting) agents kill bacteria in states of metabolic activity and division, it is not surprising that the treatment of PJI almost always requires the mechanical removal of these biofilms, ie, surgical debridement. This is also one explication why certain bacteria with the capacity to adhere and form biofilms are more prone to establish PJI. ${ }^{12}$ However, a more detailed discussion of biofilm systems is beyond the scope of this clinical review.

The most frequently retrieved organisms are Grampositive, such as S. aureus (30\%-35\% of all PJI) or Staphylococcus epidermidis. Methicillin-resistant S. aureus (MRSA) accounts for $15 \%$ of all PJI. ${ }^{1,15-17}$ Methicillin-resistant coagulase-negative staphylococci infections (eg, methicillinresistant $S$. epidermidis) are also increasingly observed in colonization and infection and account for approximately $20 \%$ of all PJI. Streptococcus spp. is responsible for $10 \%$; fungi, anaerobes, and Gram-negative rods are rarely encountered. ${ }^{18,19}$ These are all part of normal skin flora, and direct inoculation in the operating room environment is most likely responsible for PJI. Small colony variants differ from the normal staphylococcal phenotype and exhibit the ability to survive in patients in a dormant state and live inside host cells or inside their matrix. They form slow-growing colonies within the host and inside the usual incubation medium. ${ }^{20}$ Of note, the abovementioned microbiological epidemiology is an approximate average extracted from reports worldwide, and each country, and even each hospital setting, may harbor its own epidemiology, particularly for resistant organisms, as observed on many occasions. ${ }^{21}$

\section{Prevention}

Prior to joint replacement, all patients must be screened for risk factors and eventually treated. Risk factors for remote infection should be treated, such as cutaneous lesions or ulcers in the operated limb and symptomatic urinary tract infection. However, urine screening tests in asymptomatic patients are unnecessary. ${ }^{22}$ Any immunosuppressive therapy should be tapered to the lowest dose possible or discontinued (eg, anti-TNF-alpha). ${ }^{23}$ Screening for MRSA carriage appears to be cost-saving in orthopedic surgery and may help to eradicate colonization. ${ }^{24,25}$ Bacterial decolonization by showering with antiseptics, such as chlorhexidine gluconate or povidone iodine, seems to be a simple cost-effective technique to reduce PJI. ${ }^{26} \mathrm{Kim}$ et al observed also that nasal mupirocin and chlorhexidine reduced surgical site infection in MRSA carriers. ${ }^{27}$ Global health optimization for cardiac and respiratory disease, uncontrolled diabetes, and vascular insufficiency are effective for the prevention of PJI. Finally, antibiotic prophylaxis before dental interventions remains a subject of debate, but cohort studies regularly deny any objective benefit from routine prophylaxis. Hematogenous seeding to the prosthesis following dental interventions is rare, if it does exist at all, ${ }^{5}$ and complications arising from antibiotherapy appear to be more frequent. ${ }^{28}$

During joint replacement, antimicrobial prophylaxis has been proved to be effective. ${ }^{7}$ According to studies from the 1970s and 1980s, antibiotic prophylaxis helps to reduce surgical site infection from $4 \%-8 \%$ to $1 \%-3 \%$. Prosthesis fixation with antibiotic-impregnated cement is common practice and appears to reduce the rate of infection (and thus revision risk) by up to $50 \%$ compared to uncemented arthroplasty, ${ }^{5,29}$ although there can be a theoretical drawback of this strategy, eg, reduction of mechanical strength in antibiotic-impregnated cement. For parenteral prophylaxis, a first or second-generation cephalosporin is used. These are administered during 30 minutes before surgery and for not more than 24 hours, even if drains are still present. No evidence of better outcome has been shown with longer prophylaxis, but more complications were associated with prolonged antibiotic administration. One dose is generally sufficient; if the procedure takes more than 4 hours or in the case of significant blood loss, two doses may be given. ${ }^{30}$ In a prospective survey, Phillips et $\mathrm{al}^{31}$ determined that the primary infecting organism was sensitive to cefuroxime in $68 \%$ of patients with PJI. Although the organism was cefuroxime-resistant in 22 cases (29\%), no significant evidence supported the use of a broader-spectrum antibiotic (eg, vancomycin) to reduce the infection rate for patients without MRSA carriage, even in settings of high prevalence and endemicity for MRSA. ${ }^{31,32}$ Only in the case of positive carriage, glycopeptide prophylaxis is still recommended. ${ }^{5}$ Resistant internal microorganisms, such as extended-spectrum beta-lactamase and vancomycin-resistant enterococci, seem to be of less concern in orthopedic surgery compared with visceral or urologic surgery. As skin pathogens are generally predominant, expert opinion does not support any change in routine prophylaxis in the case of colonization by these pathogens. ${ }^{5}$

Intraoperative predisposing factors include simultaneous bilateral joint arthroplasty, longer operative time, increased operating room traffic, contamination by the surgical team during preparation and draping, surgical scrubs, and regular changing of the outer gloves. Hair removal immediately prior to surgery should be performed with clippers and not razors. ${ }^{33,34}$ Laminar airflow in the operating room remains 
an unresolved issue of surgical site infection prevention. However, it is still less effective than proper techniques and correction of errors in the operating room. ${ }^{35,36}$ The surgeon's operative technique and expertise that ameliorate the duration of surgery, hemostasis, gentle handling of tissue, and the eradication and removal of dead space are believed to lower the risk of infection. ${ }^{5}$ Postoperative predisposing factors to PJI include immunosuppressive medication, allogenic blood transfusion, postoperative myocardial infarction, hematoma, wound dehiscence, or longer hospital stay. ${ }^{7,15}$

\section{Diagnosis}

\section{Clinical presentation}

Acute infections are easier to diagnose due to the early presence of fever, pain, and erythema in the affected joint, with or without wound swelling. The presence of a fistula is a major sign for PJI, but this clinical sign is inconstant. In chronic joint infection, clinical signs and symptoms are unreliable and external signs are specific but insensitive. ${ }^{37}$ Constant joint pain with inflammatory patterns suggests infection in contrast to mechanical loosening that tends to cause pain with motion and weight bearing. The only relevant feature in chronic infection may be persistent painful articulation in a functional arthroplasty or early-onset loosening of the implant. Such a clinical presentation should be considered to be associated with infection until proved otherwise..$^{29,33} \mathrm{Of}$ note, fever during the first week after arthroplasty is frequent and may only reflect inflammation. Thus, it should be considered as part of the diagnosis of PJI only if other clinical manifestations or biomarkers appear relevant, or in specific cases of patients with comorbidities such as neutropenia. Fever during the first week does not influence the outcome in clean orthopedic surgery. ${ }^{38}$ In 2013, a group of international experts established a consensus regarding PJI management and diagnosis, which has been the topic of several articles in the literature. Concerning the diagnosis, this expert group agreed that PJI could be defined as 1) two positive periprosthetic cultures with a phenotypically-identical organism or 2) a sinus tract communicating with the joint or 3) having three of the following minor criteria: elevated serum C-reactive protein (CRP) and erythrocyte sedimentation rate levels; elevated synovial fluid blood cell count or a positive leukocyte esterase strip test; elevated percentage of synovial neutrophil count; positive histology; and a single positive culture. ${ }^{39}$

\section{Serum and joint inflammatory markers}

The most frequently used biomarkers are leukocytosis, erythrocyte sedimentation rate, $\mathrm{CRP}$, and procalcitonin (PCT). ${ }^{40}$
Taken separately, they are neither sensitive nor specific and can be elevated for many other reasons, although this does not necessarily rule out infection, even if they are in a normal range. The role of PCT has to be investigated further, but it appears to have a high sensitivity level and to appear positive late in arthroplasty infection, when the infection becomes systemic. In their retrospective study, Uçkay et $\mathrm{al}^{41}$ compared PCT and CRP elevation in blood and concluded that PCT was more expensive and less conclusive than CRP, without providing any additional value. The CRP level seemed to be more representative of the clinical course of the ongoing infection. Interleukin-6, released by monocytes during local infection and CRP have the highest sensitivity for the detection of PJI, ie, $96 \%$ compared with white blood cell counts and PCT. Of note, the specificity of interleukin-6 is lower as it can be released also in the presence of polyethylene particles. ${ }^{42}$ In practice, before considering revision arthroplasty in the presence of an elevated CRP, it must be determined whether any other diseases are present, such as another source of infection, neoplasia, or a collagen vascular disease, such as rheumatoid arthritis or systemic lupus erythematosus. ${ }^{37}$ If both CRP and interleukin-6 are positive in suspected PJI, an estimation of PCT level and joint aspiration are recommended before surgery. ${ }^{42}$ Inflammatory markers are not only "systemic." Many centers use the total number of leukocytes or the proportion of their subclasses in synovial fluid aspiration to diagnosis infection. ${ }^{37,39}$ However, we consider that local and systemic inflammatory markers are not a guarantee for PJI diagnosis per se as they may be elevated equally for noninfectious inflammation. Moreover, there may be also some difficulties associated with fluid culture, ie, contamination with normal skin flora.

\section{Imaging}

A plain radiograph is part of the initial management of PJI and can show abnormal lucencies or cement fractures, identify a foreign body, periosteal reaction, or changes in the position of the prosthetic component. In general, these changes appear more than 10 days after the onset of infection. The sensitivity and specificity of radiographic abnormality are $14 \%$ and $75 \%$, respectively. ${ }^{43}$ Ultrasonography is able to scan soft tissues adjacent to implants to detect fluid collection, edema, or fistulas. ${ }^{44}$ Scintigraphy with radiomarkers of infection can show an increased uptake in areas of bone with enhanced blood supply or metabolic activity. This tool is not very specific as abnormal scintigraphic changes are routinely observed in well-evolving arthroplasty several months after surgery or in the case of aseptic loosening or inflammation. Scintigraphy cannot provide bacterial identification of the 
infection, and it does not increase the probability to detect PJI in situations of chronic infection with bacteria of low virulence. ${ }^{39,45}$ Computed tomography and magnetic resonance imaging can help for the detection of deep soft tissue infection, but the metal interferes with images and results may be inconstant in PJI. For this reason, they are not considered to be a first-line diagnostic tool. ${ }^{46}$

\section{Microbiological culture and histology}

Positive culture remains the gold standard to diagnose PJI, despite its low sensitivity. Culture identifies the pathogens and their antibiotic susceptibility. Apart from S. aureus, only multiple positive cultures confirm PJI. False negatives remain frequent as a result of prior antibiotherapy, insufficient pathogen concentration, inadequate culture medium, or the time between sampling and culture. Culture requires samples of joint fluid or tissue biopsy and/or blood cultures. Tissues cultures have a better sensitivity than synovial aspiration fluid, ie, $45 \%-100 \%$ and $65 \%-94 \%$, respectively. ${ }^{47}$ Sonication of the implant lyses the biofilm. This exposes a higher inoculum for culture and thus an increased sensitivity of culture samples, especially in patients that benefited from antibiotics in the days before sampling. ${ }^{48}$ Culture growth has to be extended for more than the usual 5 days for PJI because of inappropriate medium and infection by slow-growing organisms, such as staphylococci small colony variants or Propionibacterium species. ${ }^{49}$

Polymerase chain reaction (PCR) can be useful in sterile cultures or special circumstances when difficult and slow-growing bacteria are suspected, such as Brucella spp. and Mycobacterium tuberculosis, or for detecting genes encoding for methicillin-resistance. Molecular methods shorten the time needed for an etiologic diagnosis and can potentially shorten the time of broad-spectrum antibiotic use before switching to more focused targeting antibiotics..$^{50}$ In a study comparing molecular versus microbiological methods, Rak et $a l^{50}$ found good concordance between culture and molecular methods, although cultures needed an average of 5-7 days longer to obtain final results. However, PCR has poor sensitivity, of little help in susceptibility evaluation, and its interpretation can be difficult in polymicrobial infection. ${ }^{50}$

Gram-staining has high specificity (97\%) but low sensitivity (28\%). ${ }^{51}$ Finally, a histopathologic study may reflect unusual slow-growing microorganisms, but the results are dependent on the tissue sample harboring the infection and the expertise of the pathologist; its sensitivity and specificity are approximately $80 \%$ and $90 \%$, respectively. ${ }^{52}$

\section{Therapy}

PJI management is complex and involves a combination of surgery and antimicrobial therapy, depending on the cause and timing of the infection and host conditions. ${ }^{12}$ Antibiotic use alone is not a standard therapy, and it is associated with a $>90 \%$ failure rate. There is no standardized approach for the management of PJI due to its variable clinical presentation and insufficient data from randomized trials.

\section{Surgical therapy}

In the setting of early acute onset of symptoms (less than 4 weeks after surgery) and a well-fixed prosthesis without signs of loosening, an option can be surgical debridement alone, depending on the pathogen responsible. Some authors suggest that $S$. aureus infection is a contraindication to component retention, particularly if methicillin resistant. ${ }^{53}$ The failure rate remains high (between 24\%-71\%) following debridement and irrigation. ${ }^{54,55}$ If there is an indication to remove the prosthesis, there are several treatment options. In an aseptic patient, one- or two-stage arthroplasty reimplantation can be performed without a significantly better outcome for two-stage arthroplasty, which remains the gold standard since 1970. It allows for additional debridement and optimization of the choice of antibiotic therapy and its duration, but the second intervention is more difficult to perform as a result of scarring. This option implies a hospital stay during the two interventions, and it is considered to be associated with significant morbidity and mortality, poorly tolerated by patients, and can lead to worst functional outcome and additional hospitalization costs. ${ }^{56,57}$ At present, single-stage revision arthroplasty should be considered only in selected patients in order to offer the best outcome possible. These patients need to have sufficient soft tissue, no skin fistula, no severe comorbidity, and no need for a bone graft. The microorganism must be identified before the procedure and needs to be highly sensitive to an antimicrobial agent. ${ }^{58}$ The success rate with one-stage arthroplasty can be as high as $85 \%-90 \%$; in two-stage arthroplasty, it can be higher than $90 \%$ with the use of antibiotic-impregnated cement. ${ }^{58,59}$

Some experts advocate joint aspiration before reimplantation to rule out dormant infection. However, there is no evidence base for the routine application of this approach, and it may yield false negative or false positive results. This approach depends on the patient's state and if persistent infection is suspected. ${ }^{60}$ Schindler et $a l^{60}$ reported that the detection of persistent infection during two-stage arthroplasty is best conducted on the basis of patient complaints. Following persistent infection after 6 weeks of antibiotic therapy, they 
observed that the infection level is very low and unable to be detected by standard laboratory procedures. ${ }^{60}$ No advantage of surgical exploration, Gram-staining and culture, or dosage of inflammatory markers during the second stage of arthroplasty has been shown, probably because pathogens need weeks or months to recover and reproduce an active infection. ${ }^{60,61}$ Antibiotic-impregnated, gentamicin-containing polymethylmethacrylate spacers are frequently used to diminish the adverse effect of prosthesis removal, such as soft tissue retraction, bad exposition at the time of reimplantation, or bed rest. However, there are no data confirming a better outcome of local compared to systemic and/or combined antibiotic treatment. ${ }^{62}$ Arthrodesis provides a painless and stable limb with expected shortening. Amputation can be indicated in the presence of a life-threatening infection or massive bone loss in knee arthroplasty.

\section{Antimicrobial therapy}

Initial PJI antimicrobial management begins with parenteral drugs, with a switch to enteral as early as possible so as to limit unnecessary catheter and drug complications and costs without any deleterious effect. Bone and biofilm penetration is of particular importance in osteoarticular infection. Clindamycin, linezolid, and quinolones show better ratios (between 0.3-1.2) compared to beta-lactams, such as penicillin, cephalosporins, or glycopeptides (between 0.15 and 0.3$)^{63}$ (Table 2).

\section{Choice of antibiotic agents}

The agent should act against slow-growing and biofilmproducing bacteria, such as small colony variants. Rifampin can kill staphylococci and penetrates phagocytes to kill intracellular bacteria. However, it is known to facilitate the emergence of resistant bacteria during monotherapy and should always be used in combination, ${ }^{23}$ most frequently with quinolones, such as ciprofloxacin. The most important adverse effects are drug interaction with warfarin, antihuman immunodeficiency virus drugs, antiepileptic drugs, steroids, and contraceptives. Beta-lactam antibiotics can be used parenterally, depending on the germ susceptibility, but they are known to have low oral bioavailability and intraosseous penetration, which limit their use for long-term enteral therapy $^{23}$ (Table 2).

Glycopeptides are another option. Vancomycin is a broad-spectrum antibiotic that inhibits cell wall formation. It has good penetration in infected bone but has to be administered parenterally. Oral bioavailability is around $2 \%$, and the minimal effective serum level is around $20 \mathrm{mg} / \mathrm{mL}$. However, vancomycin has numerous side effects and needs to be monitored. In general, it is used for resistant organisms or at the very beginning of infection for empirical treatment. Teicoplanin is a glycopeptide with a half-life of 72 hours. It is administered intravenously once daily or every 3 days intramuscularly with a $6-10 \mathrm{mg} / \mathrm{kg}$ dose. Daptomycin has a dose-dependent bactericidal effect. It is

Table 2 Main recommended antibiotics according to the pathogen of prosthetic joint infections (personal opinions of the authors coupled to international recommendations)

\begin{tabular}{|c|c|c|c|}
\hline Pathogens & Parenteral & Oral antibiotic & Alternative oral regimens \\
\hline Staphylococcus aureus & Flucloxacillin $4 \times 2 \mathrm{~g}$ & Ciprofloxacin $2 \times 750 \mathrm{mg}$ & Clindamycin $3 \times 600 \mathrm{mg}$ \\
\hline and coagulase-negative & Cefuroxime $3 \times 1.5 \mathrm{~g}$ & Levofloxacin $2 \times 500$ mg & Cotrimoxazole $3 \times$ double-strength \\
\hline \multirow{3}{*}{$\begin{array}{l}\text { staphylococci (methicillin- } \\
\text { sensitive) }\end{array}$} & Cefazolin $3 \times 2 \mathrm{~g}$ & Combined with rifampin & Combined with rifampin I×600 mg \\
\hline & Combined with rifampin & \multirow[t]{2}{*}{ I $\times 600 \mathrm{mg}$ if implant in place } & \multirow[t]{2}{*}{ if implant in place } \\
\hline & I $\times 600 \mathrm{mg}$ if implant in place & & \\
\hline Staphylococcus aureus & Vancomycin $2 \times 1 \mathrm{~g}$ & Fucidin acid $3 \times 500 \mathrm{mg}$ & Clindamycin $3 \times 600 \mathrm{mg}$ \\
\hline and coagulase-negative & Daptomycin $1 \times 6-8 \mathrm{mg} / \mathrm{kg}$ & Minocycline $2 \times 100 \mathrm{mg}$ & Cotrimoxazole $3 \times$ double-strength \\
\hline staphylococci (methicillin- & Combined with rifampin & Doxycycline $2 \times 100 \mathrm{mg}$ & Combined with rifampin I×600 mg \\
\hline \multirow[t]{3}{*}{ resistant) } & \multirow[t]{3}{*}{ I $\times 600 \mathrm{mg}$ if implant in place } & Linezolid $2 \times 600 \mathrm{mg}$ & \multirow[t]{3}{*}{ if implant in place } \\
\hline & & Combined with rifampin & \\
\hline & & I $\times 600 \mathrm{mg}$ if implant in place & \\
\hline Streptococci & Penicillin $6 \times 3$ million units & Clindamycin 3×600 mg & Amoxicillin $3 \times 1 \mathrm{~g}$ \\
\hline \multirow[t]{2}{*}{ Enterococci } & Penicillin $6 \times 3$ million units & \multirow[t]{2}{*}{ Amoxicillin $3 \times 1 \mathrm{~g}$} & \multirow[t]{2}{*}{ Linezolid $2 \times 600 \mathrm{mg}$} \\
\hline & Vancomycin $2 \times 1 \mathrm{~g}$ & & \\
\hline \multirow[t]{2}{*}{ Enterobacteriaceae } & Cefuroxime $3 \times 1.5 \mathrm{~g}$ & Ciprofloxacin $2 \times 750 \mathrm{mg}$ & \multirow[t]{2}{*}{ Cotrimoxazole $3 \times$ double-strength } \\
\hline & Amoxicillin/clavulanate $3 \times 1.2 \mathrm{~g}$ & Levofloxacin $2 \times 500$ mg & \\
\hline Gram-negative, nonfermenting & Ceftazidim $3 \times 2 \mathrm{~g}$ & Ciprofloxacin $2 \times 750 \mathrm{mg}$ & No oral alternatives to \\
\hline \multirow[t]{2}{*}{ rods such as Pseudomonas spp. } & Cefepime $2 \times 2 \mathrm{~g}$ & & \multirow[t]{2}{*}{ ciprofloxacin in most cases } \\
\hline & Ertapenem $\mathrm{I} \times \mathrm{Ig}$ & & \\
\hline \multirow[t]{2}{*}{ Anaerobes } & Amoxicillin/clavulanate $3 \times 1.2 \mathrm{~g}$ & Metronidazole $3 \times 500$ mg & \multirow[t]{2}{*}{ Amoxicillin/clavulanate $3 \times \lg$} \\
\hline & Metronidazole $3 \times 500 \mathrm{mg}$ & & \\
\hline
\end{tabular}


given only intravenously at a dose of $6-8 \mathrm{mg} / \mathrm{kg}$ and can treat osteoarticular infection, but some daptomycin-resistant enterococci or staphylococci have been isolated. ${ }^{64,65}$ Aminoglycosides, such as gentamicin, have low activity in synovial fluids and bone. Of note, S. aureus small colony variants, the most commonly observed pathogens in PJI, are resistant to aminoglycosides; thus, aminoglycosides should be used only in combination for sustained bacteremia. ${ }^{23,62}$ Linezolid is a bacteriostatic antibiotic with $100 \%$ bioavailability, without cross-resistance to other antibiotics. It acts essentially as an anti-Gram-positive. Inconveniences associated with its use are high cost; side effects, such as neuropathy; thrombopenia; and bone marrow suppression, but with appropriate monitoring, it is a good choice for outpatient treatment. ${ }^{23,66}$ For Gram-negative PJI, quinolones are the drugs of choice and may be the only ones available in oral form. The optimal dose is $750 \mathrm{mg}$ twice daily. ${ }^{23}$ Apart from some exceptions, such as tuberculosis, fungi or $\mathrm{Q}$ fever, there is no difference in treatment duration according to the pathogen. Even for antibiotic-resistant microorganisms, such as Pseudomonas aeruginosa and MRSA, that are associated with higher failure rates, there is no evidence that prolonging antibiotic therapy would decrease the failure rate. ${ }^{67,68}$

Strictly based on expert opinion, PJI antibiotics are usually initially administered intravenously for 1-2 weeks followed by oral therapy for 3 months if the prosthesis is retained, or 6-week oral therapy in the case of prosthesis removal. ${ }^{69}$ Following this treatment, antibiotics should be stopped, even in the presence of elevated CRP or other inflammatory parameters, as prolonging antibiotic treatment does not change the risk of recurrent PJI, which is approximately $10 \%-25 \%$. This recurrence rate is due to the pathogens involved, the quality of debridement, and patient comorbidities. ${ }^{70}$ Reimplantation is generally performed after a 2-week window following antibiotic therapy. ${ }^{69,70}$

The presence of a dedicated orthopedic infectious disease specialist has been demonstrated to have a positive impact in decreasing the duration of antibiotherapy and related costs, including collateral costs of antibiotic administration such as nursing resources and unnecessary diagnostic examinations. ${ }^{22,71}$ Finally, PJI cure rates are dependent on the pathogen and host factors. Teterycz et $a l^{68}$ compared the cure rate of arthroplasty infected by three main staphylococci, which increased from $57 \%$ for MRSA to $72 \%$ for methicillin-sensitive $S$. aureus, and to $82 \%$ for coagulase-negative staphylococci in implant infection.

\section{Summary}

Reported PJI rates remain low, but the aging population has resulted in increasing numbers of arthroplasty and revision arthroplasty procedures carried out worldwide, and surgical site infection is a potential serious threat in the future. Knowledge of the optimal diagnosis, management, and prevention is indispensable to ensure good patient outcome and entails appropriate surgical therapy combined with the judicious use of antimicrobials, particularly in an era of increasing antimicrobial resistance.

\section{Acknowledgments}

We are indebted to Mrs Rosemary Sudan for editorial assistance.

\section{Disclosure}

The authors report no conflicts of interest in this work.

\section{References}

1. Berbari EF, Hanssen AD, Duffy MC, et al. Risk factors for prosthetic joint infection: case-control study. Clin Infect Dis. 1998;27(5):1247-1254.

2. Whitehouse JD, Friedman ND, Kirkland KB, Richardson WJ, Sexton DJ The impact of surgical-site infections following orthopedic surgery at a community hospital and a university hospital: adverse quality of life, excess length of stay, and extra cost. Infect Control Hosp Epidemiol. 2002;23(4):183-189.

3. Matthews PC, Berendt AR, McNally MA, Byren I. Diagnosis and management of prosthetic joint infection. BMJ. 2009;338:b1773.

4. Kurtz S, Ong K, Lau E, Mowat F, Halpern M. Projections of primary and revision hip and knee arthroplasty in the United States from 2005 to 2030. J Bone Joint Surg Am. 2007;89(4):780-785.

5. Uçkay I, Harbarth S, Peter R, Lew D, Hoffmeyer P, Pittet D. Preventing surgical site infections. Expert Rev Anti Infect Ther. 2010;8(6): 657-670.

6. Tsaras G, Osmon DR, Mabry T, et al. Incidence, secular trends, and outcomes of prosthetic joint infection: a population-based study, olmsted county, Minnesota, 1969-2007. Infect Control Hosp Epidemiol. 2012;33(12):1207-1212.

7. Jämsen E, Huhtala H, Puolakka T, Moilanen T. Risk factors for infection after knee arthroplasty. A register-based analysis of 43,149 cases. J Bone Joint Surg Am. 2009;91(1):38-47.

8. Widmer AF, Rotter M, Voss A, et al. Surgical hand preparation: stateof-the-art. J Hosp Infect. 2010;74(2):112-122.

9. Prokuski L. Prophylactic antibiotics in orthopaedic surgery. J Am Acad Orthop Surg. 2008;16(5):283-293.

10. Murdoch DR, Roberts SA, Fowler VG Jr, et al. Infection of orthopedic prostheses after Staphylococcus aureus bacteremia. Clin Infect Dis. 2001;32(4):647-649.

11. Uçkay I, Lübbeke A, Emonet S, et al. Low incidence of haematogenous seeding to total hip and knee prostheses in patients with remote infections. J Infect. 2009;59(5):337-345.

12. Uçkay I, Pittet D, Vaudaux P, Sax H, Lew D, Waldvogel F. Foreign body infections due to Staphylococcus epidermidis. Ann Med. 2009;41(2): 109-119.

13. Bouvet C, Tchernin D, Seirafi M, et al. No need to search for the source of haematogenous arthroplasty infections. Swiss Med Wkly. 2011;141:w13306.

14. Gristina AG. Biomaterial-centered infection: microbial adhesion versus tissue integration. Science. 1987;237(4822):1588-1595. 
15. Pulido L, Ghanem E, Joshi A, Purtill JJ, Parvizi J. Periprosthetic joint infection: the incidence, timing, and predisposing factors. Clin Orthop Relat Res. 2008;466(7):1710-1715.

16. Buller LT, Sabry FY, Easton RW, Klika AK, Barsoum WK. The preoperative prediction of success following irrigation and debridement with polyethylene exchange for hip and knee prosthetic joint infections. J Arthroplasty. 2012;27(6):857-864.

17. Corvec S, Portillo ME, Pasticci BM, Borens O, Trampuz A. Epidemiology and new developments in the diagnosis of prosthetic joint infection. Int J Artif Organs. 2012;35(10):923-934.

18. Zmistowski B, Fedorka CJ, Sheehan E, Deirmengian G, Austin MS, Parvizi J. Prosthetic joint infection caused by gram-negative organisms. J Arthroplasty. 2011;26(Suppl 6):104-108.

19. Anagnostakos K, Kelm J, Schmitt E, Jung J. Fungal periprosthetic hip and knee joint infections clinical experience with a 2-stage treatment protocol. J Arthroplasty. 2012;27(2):293-298.

20. Sendi P, Rohrbach M, Graber P, Frei R, Ochsner PE, Zimmerli W. Staphylococcus aureus small colony variants in prosthetic joint infection. Clin Infect Dis. 2006;43(8):961-967.

21. Aggarwal VK, Bakhshi H, Ecker NU, Parvizi J, Gehrke T, Kendoff D. Organism profile in periprosthetic joint infection: pathogens differ at two arthroplasty infection referral centers in Europe and in the United States. J Knee Surg. 2014;27(5):399-406.

22. Bouvet $C$, Lübbeke $A, B a n d i ~ C$, et al. Is there any benefit in pre-operative urinary analysis before elective total joint replacement? Bone Joint $J$. 2014;96-B(3):390-394.

23. Pieringer H, Stuby U, Biesenbach G. Patients with rheumatoid arthritis undergoing surgery: how should we deal with antirheumatic treatment? Semin Arthritis Rheum. 2007;36(5):278-286.

24. De Lucas-Villarrubia JC, Lopez-Franco M, Granizo JJ, De LucasGarcia JC, Gomez-Barrena E. Strategy to control methicillin-resistant Staphylococcus aureus post-operative infection in orthopaedic surgery. Int Orthop. 2004;28(1):16-20.

25. Larkin SA, Murphy BS. Preoperative decolonization of methicillinresistant Staphylococcus aureus. Orthopedics. 2008;31(1):37-41.

26. Mangram AJ, Horan TC, Pearson ML, Silver LC, Jarvis WR. Guideline for prevention of surgical site infection, 1999. Centers for Disease Control and Prevention (CDC) Hospital Infection Control Practices Advisory Committee. Am J Infect Control. 1999;27(2):97-134; discussion 96.

27. Kim DH, Spencer M, Davidson SM, et al. Institutional prescreening for detection and eradication of methicillin-resistant Staphylococcus aureus in patients undergoing elective orthopaedic surgery. J Bone Joint Surg Am. 2010;92(9):1820-1826.

28. Uçkay I, Pittet D, Bernard L, Lew D, Perrier A, Peter R. Antibiotic prophylaxis before invasive dental procedures in patients with arthroplasties of the hip and knee. J Bone Joint Surg Br. 2008;90(7):833-838.

29. Parvizi J, Saleh KJ, Ragland PS, Pour AE, Mont MA. Efficacy of antibiotic-impregnated cement in total hip replacement. Acta Orthop. 2008;79(3):335-341.

30. Matar WY, Jafari SM, Restrepo C, Austin M, Purtill JJ, Parvizi J. Preventing infection in total joint arthroplasty. J Bone Joint Surg Am. 2010;92(Suppl 2):36-46.

31. Phillips JE, Crane TP, Noy M, Elliott TS, Grimer RJ. The incidence of deep prosthetic infections in a specialist orthopaedic hospital: a 15-year prospective survey. J Bone Joint Surg Br. 2006;88(7):943-948.

32. Bolon MK, Morlote M, Weber SG, Koplan B, Carmeli Y, Wright SB. Glycopeptides are no more effective than beta-lactam agents for prevention of surgical site infection after cardiac surgery: a meta-analysis. Clin Infect Dis. 2004;38(10):1357-1363.

33. Cassar Gheiti AJ, Mulhall KJ. Peri-prosthetic joint infection: prevention, diagnosis and management. In: Kinov P, editor. Arthroplasty - Update. InTech; 2013:481 -515.

34. Niël-Weise BS, Wille JC, van den Broek PJ. Hair removal policies in clean surgery: systematic review of randomized, controlled trials. Infect Control Hosp Epidemiol. 2005;26(12):923-928.
35. Evans RP. Current concepts for clean air and total joint arthroplasty: laminar airflow and ultraviolet radiation: a systematic review. Clin Orthop Rel Res. 2011;469(4):945-953.

36. Brandt C, Hott U, Sohr D, Daschner F, Gastmeier P, Rüden H. Operating room ventilation with laminar airflow shows no protective effect on the surgical site infection rate in orthopedic and abdominal surgery. Ann Surg. 2008;248(5):695-700.

37. Bernard L, Lübbeke A, Stern R, et al; Groupe D'Etude Sur L'Ostéite. Value of preoperative investigations in diagnosing prosthetic joint infection: retrospective cohort study and literature review. Scand J Infect Dis. 2004;36(6-7):410-416.

38. Uçkay I, Agostinho A, Stern R, Bernard L, Hoffmeyer P, Wyssa B. Occurrence of fever in the first postoperative week does not help to diagnose infection in clean orthopaedic surgery. Int Orthop. 2011;35(8): $1257-1260$.

39. Schwarz EM, Kates SL, Alt V. The 1st International Consensus Meeting on Periprosthetic Joint Infection. J Orthop Res. 2014;32(Suppl 1):S1.

40. Alijanipour P, Bakhshi H, Parvizi J. Diagnosis of periprosthetic joint infection: the threshold for serological markers. Clin Orthop Relat Res. 2013;471(10):3186-3195.

41. Uçkay I, Garzoni C, Ferry T, et al. Postoperative serum pro-calcitonin and C-reactive protein levels in patients with orthopedic infections. Swiss Med Wkly. 2010;140:w13124.

42. Bottner F, Wegner A, Winkelmann W, Becker K, Erren M, Götze C. Interleukin-6, procalcitonin and TNF-alpha: markers of peri-prosthetic infection following total joint replacement. J Bone Joint Surg Br. 2007; 89(1):94-99.

43. Tumeh SS, Aliabadi P, Weissman BN, McNeil BJ. Disease activity in osteomyelitis: role of radiography. Radiology. 1987;165(3):781-784.

44. Venkatesh SK, Riederer B, Chhem RK, Cardinal E, Wang SC. Reactivation in post-traumatic chronic osteomyelitis: ultrasonographic findings. Can Assoc Radiol J. 2003;54(3):163-168.

45. Smith SL, Wastie ML, Forster I. Radionuclide bone scintigraphy in the detection of significant complications after total knee joint replacement. Clin Radiol. 2001;56(3):221-224.

46. Saeed K. Diagnostics in prosthetic joint infections. J Antimicrob Chemother. 2014;69(Suppl 1):i11-i19.

47. Trampuz A, Osmon DR, Hanssen AD, Steckelberg JM, Patel R. Molecular and antibiofilm approaches to prosthetic joint infection. Clin Orthop Rel Res. 2003;(414):69-88.

48. Trampuz A, Piper KE, Hanssen AD, et al. Sonication of explanted prosthetic components in bags for diagnosis of prosthetic joint infection is associated with risk of contamination. J Clin Microbiol. 2006;44(2): 628-631.

49. Widmer AF. New developments in diagnosis and treatment of infection in orthopedic implants. Clin Infect Dis. 2001;33(Suppl 2): S94-S106.

50. Rak M, Barlič-Maganja D, Kavčič M, Trebše R, Cör A. Comparison of molecular and culture method in diagnosis of prosthetic joint infection. FEMS Microbiol Lett. 2013;343(1):42-48.

51. Cunningham G, Seghrouchni K, Ruffieux E, et al. Gram and acridine orange staining for diagnosis of septic arthritis in different patient populations. Int Orthop. 2014;38(6):1283-1290.

52. Uçkay I, Teterycz D, Ferry T, et al. Poor utility of MRSA screening to predict staphylococcal species in orthopaedic implant infections. $J$ Hosp Infect. 2009;73(1):89-91.

53. Bradbury T, Fehring TK, Taunton M, et al. The fate of acute methicillinresistant Staphylococcus aureus periprosthetic knee infections treated by open debridement and retention of components. J Arthroplasty. 2009; 24(Suppl 6):101-104.

54. Tsukayama DT, Estrada R, Gustilo RB. Infection after total hip arthroplasty. A study of the treatment of one hundred and six infections. J Bone Joint Surg Am. 1996;78(4):512-523.

55. Crockarell JR, Hanssen AD, Osmon DR, Morrey BF. Treatment of infection with debridement and retention of the components following hip arthroplasty. J Bone Joint Surg Am. 1998;80(9):1306-1313. 
56. Lange J, Troelsen A, Thomsen RW, Søballe K. Chronic infections in hip arthroplasties: comparing risk of reinfection following one-stage and two-stage revision: a systematic review and meta-analysis. Clin Epidemiol. 2012;4:57-73.

57. Leonard HA, Liddle AD, Burke O, Murray DW, Pandit H. Single- or twostage revision for infected total hip arthroplasty? A systematic review of the literature. Clin Orthop Relat Res. 2014;472(3):1036-1042.

58. Winkler H. Rationale for one stage exchange of infected hip replacement using uncemented implants and antibiotic impregnated bone graft. Int J Med Sci. 2009;6(5):247-252.

59. Hsieh PH, Shih CH, Chang YH, Lee MS, Shih HN, Yang WE. Two-stage revision hip arthroplasty for infection: comparison between the interim use of antibiotic-loaded cement beads and a spacer prosthesis. $J$ Bone Joint Surg Am. 2004;86-A(9):1989-1997.

60. Schindler M, Christofilopoulos P, Wyssa B, et al. Poor performance of microbiological sampling in the prediction of recurrent arthroplasty infection. Int Orthop. 2011;35(5):647-654.

61. Müller M, Morawietz L, Hasart O, Strube P, Perka C, Tohtz S. Diagnosis of periprosthetic infection following total hip arthroplasty - evaluation of the diagnostic values of pre- and intraoperative parameters and the associated strategy to preoperatively select patients with a high probability of joint infection. J Orthop Surg Res. 2008;3:31.

62. Barth RE, Vogely HC, Hoepelman AI, Peters EJ. 'To bead or not to bead?' Treatment of osteomyelitis and prosthetic joint-associated infections with gentamicin bead chains. Int JAntimicrob Agents. 2011;38(5): $371-375$.

63. Landersdorfer CB, Bulitta JB, Kinzig M, Holzgrabe U, Sörgel F. Penetration of antibacterials into bone: pharmacokinetic, pharmacodynamic and bioanalytical considerations. Clin Pharmacokinet. 2009; 48(2):89-124.
64. Jugun K, Vaudaux P, Garbino J, et al. The safety and efficacy of high-dose daptomycin combined with rifampin for the treatment of Gram-positive osteoarticular infections. Int Orthop. 2013;37(7):1375-1380.

65. Marty FM, Yeh WW, Wennersten CB, et al. Emergence of a clinical daptomycin-resistant Staphylococcus aureus isolate during treatment of methicillin-resistant Staphylococcus aureus bacteremia and osteomyelitis. J Clin Microbiol. 2006;44(2):595-597.

66. Bishop E, Melvani S, Howden BP, Charles PG, Grayson ML. Good clinical outcomes but high rates of adverse reactions during linezolid therapy for serious infections: a proposed protocol for monitoring therapy in complex patients. Antimicrob Agents Chemother. 2006;50(4):1599-1602.

67. Seghrouchni K, van Delden C, Dominguez D, et al. Remission after treatment of osteoarticular infections due to Pseudomonas aeruginosa versus Staphylococcus aureus: a case-controlled study. Int Orthop. 2012;36(5):1065-1071.

68. Teterycz D, Ferry T, Lew D, et al. Outcome of orthopedic implant infections due to different staphylococci. Int J Infect Dis. 2010;14(10): e913-e918.

69. Bernard L, Legout L, Zürcher-Pfund L, et al. Six weeks of antibiotic treatment is sufficient following surgery for septic arthroplasty. J Infect. 2010;61(2):125-132.

70. Piso RJ, Elke R. Antibiotic treatment can be safely stopped in asymptomatic patients with prosthetic joint infections despite persistent elevated C-reactive protein values. Infection. 2010;38(4): 293-296.

71. Uçkay I, Vernaz-Hegi N, Harbarth S, et al. Activity and impact on antibiotic use and costs of a dedicated infectious diseases consultant on a septic orthopaedic unit. J Infect. 2009;58(3):205-212.
Orthopedic Research and Reviews

\section{Publish your work in this journal}

Orthopedic Research and Reviews is an international, peer-reviewed, open access journal focusing on the patho-physiology of the musculoskeletal system, trauma, surgery and other corrective interventions to restore mobility and function. Advances in new technologies, materials, techniques and pharmacological agents are particularly welcome. The journal welcomes

\section{Dovepress}

original research, clinical studies, reviews \& evaluations, expert opinion and commentary, case reports and extended reports. The manuscript management system is completely online and includes a very quick and fair peer-review system, which is all easy to use. Visit http://www.dovepress. com/testimonials.php to read real quotes from published authors. 